\title{
Review Article \\ The Impact of Endometriosis across the Lifespan of Women: Foreseeable Research and Therapeutic Prospects
}

\author{
C. L. Hughes, ${ }^{1,2}$ W. G. Foster, ${ }^{3}$ and S. K. Agarwal ${ }^{4}$ \\ ${ }^{1}$ Cardiovascular \& Metabolic Diseases, Medical Strategy \& Science, Quintiles, Inc., 5927 S. Miami Boulevard, \\ Morrisville, NC 27560, USA \\ ${ }^{2}$ Department of Obstetrics and Gynecology, Duke University Medical Center, Durham, NC 27710, USA \\ ${ }^{3}$ Department of Obstetrics and Gynecology, McMaster University, Hamilton, ON, Canada L8S 4L8 \\ ${ }^{4}$ Department of Reproductive Medicine, University of California-San Diego, San Diego, CA 92093-0633, USA
}

Correspondence should be addressed to C. L. Hughes; claude.hughes@quintiles.com

Received 18 November 2014; Accepted 12 January 2015

Academic Editor: Mariela Bilotas

Copyright (C) 2015 C. L. Hughes et al. This is an open access article distributed under the Creative Commons Attribution License, which permits unrestricted use, distribution, and reproduction in any medium, provided the original work is properly cited.

In addition to estrogen dependence, endometriosis is characterized by chronic pelvic inflammation. The impact of the chronic pelvic inflammatory state on other organ systems and women's health is unclear. Endometriosis associated chronic inflammation and potential adverse health effects across the lifespan render it imperative for renewed research vigor into the identification of novel biomarkers of disease and therapeutic options. Herein we propose a number of opportunities for research and development of new therapeutics to address the unmet needs in the treatment of endometriosis per se and its ancillary risks for other diseases in women across the lifespan.

\section{Introduction}

Although a number of causal or exacerbatory pathological mechanisms seem to underlie initiation and persistence or progression of endometriosis [1-12] there is no debate that this disease features a chronic inflammatory state within the peritoneal cavity $[9,10]$. The extent to which this disease process impacts the health of women surely relates to inflammation within this anatomical/physiological compartment. As a corollary, it is plausible that systemic chronic inflammatory effects also result and endometriosis could induce adverse effects on other tissues or body systems. Given the broad and widely accepted notion that chronic inflammation is a risk factor for various degenerative or "Western Diseases" such as atherosclerosis, multiple cancers, dementias, degenerative joint diseases, inflammatory bowel diseases, and others, endometriosis must be considered as a potential risk factor for a spectrum of other diseases that may adversely impact the health of women across the lifespan. If one or more such associations are established and one or more causal relationships can be demonstrated, then medical care of these young adult patients will be driven by additional imperatives that will extend far beyond those extremely important health impacts that are currently recognized related to loss of fertility, debilitating pain, and destruction of urogenital and gastrointestinal tissues and organs. Our endometriosis patients deserve insightful and expert care for all of the potential types of harm that this disease can incur. From this perspective, we will summarize or propose a number of opportunities for research and development of new therapeutics to address the unmet needs in the treatment of endometriosis per se and its ancillary risks for other diseases in women across the lifespan.

\section{Causality in the Association of Endometriosis and Intraperitoneal Inflammation}

The association of endometriosis with intraperitoneal inflammation is thoroughly acknowledged by physicians and investigators in this field. The causal relationship regarding which 
comes first may not be absolutely established [3] but research with nonhuman primate models strongly supports the contention that the initiation of endometriosis implants triggers the inflammatory effects rather than the other way around [13]. It is quite possible that endometriosis is both the result of and the cause of further inflammation.

\section{Key Issues in Understanding and Managing the Effects of Endometriosis across the Lifespan}

No matter whether the disease etiology depends primarily upon the biomechanics of retrograde menstruation, sex hormone modulation of endometrial tissue proliferation, environmental exposures, genetics, oxidative stress, or inflammatory cell populations, we must address three key themes:

(1) we must develop novel biomarkers of endometriosis for diagnosis, response to treatment, and disease progression;

(2) we must ascertain whether the chronic inflammatory process in the peritoneal compartment incurs a significant risk for other systemic (remote) diseases [1418 ;

(3) we must strive to identify novel preventative, modulatory, or therapeutic interventions that can take advantage of cellular and molecular mechanisms to mitigate both the primary disease process (intraperitoneal endometriosis) and the consequent systemic inflammatory effects.

\section{Innovations in the Search for a Biomarker of Endometriosis}

A plethora of biochemical differences in the peripheral circulation, peritoneal fluid, and endometrial tissues of women with endometriosis versus healthy controls has been demonstrated [40-42] many of which are related to a chronic inflammatory reaction [43-50]. Other biomarkers that have been examined include vascular endothelial growth factor (VEGF) [51-53], glycodelin [54-56], different biomarkers in the apoptosis pathway including the annexin family [5759], and soluble intracellular adhesion molecule-1 [60-63]. Of the vast number of factors that have received attention as potential diagnostic biomarkers of endometriosis, cancer antigen 125 (CA125) is potentially the most widely studied [46, 64-66]. However, use of CA125 as a single diagnostic biomarker of endometriosis is unacceptable owing to low sensitivity [67]. While the search for clinically useful markers of endometriosis continues, there is growing evidence that a compact panel of molecular markers may show the performance characteristics needed to serve as a practical screening or diagnostic test, especially if used as part of a multiparameter mathematical model [50, 68-70].

Emerging areas of interest include nerve fiber density, microRNA (miRNA), and neurotrophins. Recent studies report the fact that nerve fiber density in the functional layer of the eutopic endometrium is greater in women with endometriosis compared to controls [71, 72]. Although this conclusion was recently challenged [73], the measurement of nerve fiber density has been put forward as a diagnostic tool for mild to minimal endometriosis [74]. Unfortunately, measurement of nerve fiber density requires an endometrial biopsy and thus is more technically demanding, painful, time consuming, and resource intensive than a simple blood test and is therefore potentially less appealing to women and their health care providers. In contrast, mean plasma concentrations of the neurotrophin, brain derived neurotrophic factor (BDNF), were greater than 2 times higher in women with endometriosis versus healthy asymptomatic controls whilst no differences were found at three months after surgical removal of lesions [75]. Moreover, increased expression of BDNF and neurotrophin $4 / 5$ has been demonstrated in the endometrium of women with endometriosis versus healthy controls [76]. Taken together these studies suggest that the neurotrophins could hold promise as biomarkers of endometriosis.

Several recent studies have documented aberrant expression of several different miRNAs in women with endometriosis [77-82]. miRNAs are short noncoding RNAs that negatively regulate mRNA translation by repressing the protein translational machinery or degrading their target transcripts. Greater than 2000 mature human miRNA sequences have been identified and are thought to regulate approximately $50 \%$ of all protein coding genes. Although widely studied in cancer, the role of miRNAs in regulation of proteins important in the pathophysiology of endometriosis is relatively unexplored. Unfortunately, we could find no agreement amongst the miRNA changes documented in the studies conducted to date [77-82] which we suggest arises from differences in tissues sampled (deep infiltrating, peritoneal, or endometrioma), burden of disease, type of lesion (red, blue-black versus white), and failure to adequately control for confounding factors [83].

Prospects for development of improved diagnostic and disease-monitoring strategies for endometriosis have recently been advanced by the efforts of a major international research consortium, the international "WERF EPHect" initiative [8488]. In this important research program, major strides have been made regarding the bases for harmonizing the way data, surgical phenotype, tissues, and fluid samples are collected and should serve as a critical basis for more coherent future research in this field.

\section{Evidence Regarding Systemic Inflammation and Disease Associations in Women with Endometriosis}

Contemporary biomarker techniques [17] are beginning to demonstrate the range of molecules that can be detected systemically in women with endometriosis that are plausibly related to the range of autoimmune and other inflammatory disorders that have been associated by survey research [89]. A modest number of studies have been published suggesting that risk factors for and an increased occurrence of a number 
of chronic diseases occur in women with endometriosis [9094]. The range of associated diseases is relatively wide but largely hinges on the concept that chronic inflammation and oxidative stress are systemically increased in the women with endometriosis and these pathways are a plausible basis for such associations and perhaps in due course evidence of causation. Endometriosis is not the only reproductive tract related inflammatory process that has been implicated in the risks associated with systemic inflammation since endothelial dysfunction has also been demonstrated in men with chronic prostatitis and chronic pelvic pain syndrome [95]. The impact of benign but chronic reproductive tract diseases in both sexes merit committed research and development of safe and effective therapeutics.

\section{Unique Considerations for the Therapeutic Challenge When Considering the Impact of Endometriosis across the Lifespan}

Current therapeutic drugs are primarily directed at suppressing the intraperitoneal activity of the underlying disease. As is the case for other chronic diseases, future novel therapeutics for endometriosis will need to be developed to treat the primary intraperitoneal process [20], the potential associated intraperitoneal malignant $\operatorname{risk}(\mathrm{s})[96,97]$, and the potentially distant disease risk factors [98]. New lifespan therapies that treat either the primary intraperitoneal process or both endometriosis per se and systemic adverse effects with durability will mean either long-term continuing usage or repetitive episodic usage with convincing evidence of patient safety and tolerability. Accordingly investigators in this field need to consider the prospects for patient safety with chronic usage of any candidate agents along with evidence of efficacy and reduction in risks of other diseases associated with chronic inflammation [99]. Whether diet is considered broadly [100] or in terms of specific food groups [101] aimed at reduction of risks of multiple chronic diseases, humans in general do not consume the quantities of vegetables and fruits that would afford beneficial effects as seen with higher levels of healthful protective dietary phytochemicals. For more targeted management of endometriosis, we should study dietary (nutritional and functional) interventions, generally recognized as safe (GRAS) compounds, and repurposing of established pharmaceuticals as well as novel compounds for efficacy but all must also be assessed with this long-term safety imperative in mind.

Beyond the current set of hormonal and anti-inflammatory drugs used to treat endometriosis, what classes of compounds might be safe and effective in the sustained management of this chronic inflammatory process? A modest number of ideas have been suggested by various investigators and we shall consider them plus one new idea that we propose from some recent research in continuous ambulatory peritoneal dialysis (CAPD).

Several classes of compounds (Table 1) have been or could be directed toward development as therapeutics for the intraperitoneal compartment aspects of endometriosis $[1,19-30]$. Several of these would modify inflammation or oxidative stress by one mode of action or another while others could be developed to affect implantation and survival of endometriosis implants or to mitigate some of the actions of cellular mediators of endometriosis associated inflammation.

The second group of compounds that merit research and development for potential application in endometriosis may potentially mitigate both the intraperitoneal and the systemic inflammatory consequences of endometriosis [20, 34-39]. On one hand, the recent evidence that omega- 3 fatty acids may have anti-inflammatory effects in monocytes by acting on the GPR120 receptor [38] raises the attractive prospect that a dietary or nutritional supplement could be shown to benefit women with endometriosis. The opportunity to repurpose or extend the indications for well-known pharmaceuticals $[20,34,35]$ to use in the long-term care of women with endometriosis could also offer options for subpopulations of patients who have concomitant disorders such as dyslipidemia or glucose intolerance/type II diabetes mellitus whether we are or are not able to attribute their metabolic disorders to the presumed risk of antecedent or ongoing endometriosis. Another drug repurposing prospect is the gout therapy, colchicine. This well-known anti-inflammatory drug has been used for decades and has a well-established safety record when used chronically to suppress recurrent flares of gout [37]. Additionally, a recent study in an animal model of endometriosis showed colchicine to be highly effective in suppressing intraperitoneal implant volumes and concentrations of TNF- $\alpha$ in peritoneal fluid [38]. Finally, based on a new study in an animal model of continuous ambulatory peritoneal dialysis (CAPD) in which oral administration of spironolactone was remarkably effective at decreasing intraperitoneal fibrosis and inflammation [36] and since reproductive endocrinology and infertility subspecialists have substantial experience with the safe chronic use of spironolactone in women with androgen excess disorders, we urge investigators to consider research to assess the therapeutic potential of spironolactone or other aldosterone receptor antagonists in endometriosis.

\section{Summary and Prospects for Future Therapeutic Developments}

It is our view that there are ample opportunities to pursue research regarding the impact of endometriosis across the lifespan and to pursue development of a number of therapeutics that could plausibly be expected to be both safe and beneficial for women suffering with this disease. This is not an argument for taking our eye off the prize meaning endometriosis as the primary disease; rather we owe it to each of our patients to consider all of the impacts at all times in life that this disease may incur. We urge deeper and broader understanding of such risks and pursuit of safe and effective interventions for the care of our patients. 
TABLE 1: Possible future therapeutics for endometriosis and endometriosis-related systemic inflammation.

\begin{tabular}{|c|c|c|c|}
\hline Representative compound & Class/category & Mode(s) of action & Representative references \\
\hline \multicolumn{4}{|c|}{ Intraperitoneal compartment: disease process and inflammation } \\
\hline Pycnogenol & Diet/supplement & $\begin{array}{c}\text { Nuclear factor-kappa B } \\
\text { inhibitor }\end{array}$ & {$[19]$} \\
\hline Novel compounds & Pharmaceuticals & Angiogenesis inhibition & {$[20,21]$} \\
\hline $\begin{array}{l}\text { Resveratrol, other novel } \\
\text { compounds }\end{array}$ & $\begin{array}{l}\text { Diet/supplement or } \\
\text { pharmaceuticals }\end{array}$ & $\begin{array}{c}\text { Sirtuin } 1 \\
\text { pathway/anti-inflammatory }\end{array}$ & {$[22]$} \\
\hline Melatonin & Supplement & Antioxidant & {$[23-25]$} \\
\hline $\begin{array}{l}\text { Novel compounds, vitamin } \\
\text { D/analogues }\end{array}$ & $\begin{array}{l}\text { Pharmaceuticals or vitamin } \\
\text { D plus progesterone }\end{array}$ & $\begin{array}{c}\text { Semaphorins and } \\
\text { plexins/cell attachment }\end{array}$ & {$[26-29]$} \\
\hline $\begin{array}{l}\text { Novel biopharmaceutical } \\
\text { compounds }\end{array}$ & siRNA & Inflammatory monocytes & {$[30]$} \\
\hline AH6809, AH23848 & $\begin{array}{c}\text { Prostaglandin E2 receptor } \\
\text { (PTGER2 or PTGER4) } \\
\text { antagonists }\end{array}$ & $\begin{array}{l}\text { Prostaglandin E2 } \\
\text { antagonism }\end{array}$ & {$[31-33]$} \\
\hline Novel compounds & $\begin{array}{c}\text { Histone deacetylase } \\
\text { inhibitors }\end{array}$ & Epigenetic modification & {$[1]$} \\
\hline \multicolumn{4}{|c|}{ Intraperitoneal and systemic inflammation: interface between compartments } \\
\hline Statins & $\begin{array}{c}\text { Well-known } \\
\text { pharmaceuticals }\end{array}$ & $\begin{array}{c}\text { Inhibition of HMG-CoA } \\
\text { reductase and } \\
\text { anti-inflammatory }\end{array}$ & {$[20,34]$} \\
\hline Metformin & $\begin{array}{l}\text { Well-known } \\
\text { pharmaceutical }\end{array}$ & Anti-inflammatory & {$[35]$} \\
\hline $\begin{array}{l}\text { Omega-3-fatty acid, novel } \\
\text { compounds }\end{array}$ & $\begin{array}{l}\text { Diet/supplement or } \\
\text { pharmaceuticals }\end{array}$ & $\begin{array}{l}\text { Anti-inflammatory and } \\
\text { inflammatory monocytes } \\
\text { via GPR120 }\end{array}$ & {$[36]$} \\
\hline $\begin{array}{l}\text { Spironolactone (recent } \\
\text { study in CAPD) }\end{array}$ & $\begin{array}{l}\text { Well-known } \\
\text { pharmaceutical }\end{array}$ & $\begin{array}{l}\text { Intraperitoneal and } \\
\text { systemic inflammatory via } \\
\text { aldosterone receptor } \\
\text { antagonism }\end{array}$ & {$[37]$} \\
\hline Colchicine & $\begin{array}{c}\text { Well-known } \\
\text { pharmaceutical }\end{array}$ & $\begin{array}{l}\text { Intraperitoneal and } \\
\text { systemic inflammatory via } \\
\text { multiple modes of action }\end{array}$ & {$[38,39]$} \\
\hline
\end{tabular}

\section{Conflict of Interests}

The authors declare that there is no conflict of interests regarding the publication of this paper.

\section{References}

[1] S.-W. Guo, "Epigenetics of endometriosis," Molecular Human Reproduction, vol. 15, no. 10, pp. 587-607, 2009.

[2] K. Vijaya Lakshmi, P. Shetty, K. Vottam, S. Govindhan, S. N. Ahmad, and Q. Hasan, "Tumor necrosis factor alpha -C850T polymorphism is significantly associated with endometriosis in Asian Indian women," Fertility and Sterility, vol. 94, no. 2, pp. 453-456, 2010.

[3] H. Kajihara, Y. Yamada, S. Kanayama et al., "New insights into the pathophysiology of endometriosis: from chronic inflammation to danger signal," Gynecological Endocrinology, vol. 27, no. 2, pp. 73-79, 2011.

[4] R. O. Burney and L. C. Giudice, "Pathogenesis and pathophysiology of endometriosis," Fertility and Sterility, vol. 98, no. 3, pp. 511-519, 2012.

[5] A. Augoulea, A. Alexandrou, M. Creatsa, N. Vrachnis, and I. Lambrinoudaki, "Pathogenesis of endometriosis: the role of genetics, inflammation and oxidative stress," Archives of Gynecology and Obstetrics, vol. 286, no. 1, pp. 99-103, 2012.

[6] S. Vichi, E. Medda, A. M. Ingelido et al., "Glutathione transferase polymorphisms and risk of endometriosis associated with polychlorinated biphenyls exposure in Italian women: a gene-environment interaction," Fertility and Sterility, vol. 97, no. 5, pp. 1143.e3-1151.e3, 2012.

[7] S. J. Han, S. M. Hawkins, K. Begum et al., "A new isoform of steroid receptor coactivator-1 is crucial for pathogenic progression of endometriosis," Nature Medicine, vol. 18, no. 7, pp. 1102-1111, 2012.

[8] D. Kirchhoff, S. Kaulfuss, U. Fuhrmann, M. Maurer, and T. M. Zollner, "Mast cells in endometriosis: guilty or innocent bystanders?" Expert Opinion on Therapeutic Targets, vol. 16, no. 3, pp. 237-241, 2012.

[9] I. Ilie and R. Ilie, "Cytokines and endometriosis-the role of immunological alterations," Biotechnology, Molecular Biology and Nanomedicine, vol. 1, no. 2, pp. 8-19, 2013.

[10] H. Kobayashi, Y. Higashiura, H. Shigetomi, and H. Kajihara, "Pathogenesis of endometriosis: the role of initial infection and subsequent sterile inflammation (Review)," Molecular Medicine Reports, vol. 9, no. 1, pp. 9-15, 2014. 
[11] P. Vercellini, P. Viganò, E. Somigliana, and L. Fedele, "Endometriosis: pathogenesis and treatment," Nature Reviews Endocrinology, vol. 10, no. 5, pp. 261-275, 2014.

[12] S. Sourial, N. Tempest, and D. K. Hapangama, "Theories on the pathogenesis of endometriosis," International Journal of Reproductive Medicine, vol. 2014, Article ID 179515, 9 pages, 2014.

[13] T. M. D’Hooghe, C. M. Kyama, D. Chai et al., "Nonhuman primate models for translational research in endometriosis," Reproductive Sciences, vol. 16, no. 2, pp. 152-161, 2009.

[14] C. S. D. Roxburgh and D. C. McMillan, "Cancer and systemic inflammation: treat the tumour and treat the host," British Journal of Cancer, vol. 110, no. 6, pp. 1409-1412, 2014.

[15] M. Dutta, M. Joshi, S. Srivastava, I. Lodh, B. Chakravarty, and K. Chaudhury, "A metabonomics approach as a means for identification of potential biomarkers for early diagnosis of endometriosis," Molecular BioSystems, vol. 8, no. 12, pp. 3281-3287, 2012.

[16] H.-G. Lee, "Mining the biomarker from the blood of patients with endometriosis using proteomics and metabolomics approach," in Proceedings of the International Conference and Exhibition on Metabolomics \& Systems Biology, p. 1, 2012.

[17] S. K. Jana, M. Dutta, M. Joshi, S. Srivastava, B. Chakravarty, and K. Chaudhury, "1H NMR based targeted metabolite profiling for understanding the complex relationship connecting oxidative stress with endometriosis," BioMed Research International, vol. 2013, Article ID 329058, 9 pages, 2013.

[18] Y. B. Aznaurova, M. B. Zhumataev, T. K. Roberts, A. M. Aliper, and A. A. Zhavoronkov, "Molecular aspects of development and regulation of endometriosis," Reproductive Biology and Endocrinology, vol. 12, article 50, 2014.

[19] H. Maia Jr., C. Haddad, and J. Casoy, "Combining oral contraceptives with a natural nuclear factor-kappa $b$ inhibitor for the treatment of endometriosis-related pain," International Journal of Women's Health, vol. 6, no. 1, pp. 35-39, 2014.

[20] P. G. A. Hompes and V. Mijatovic, "Endometriosis: the way forward," Gynecological Endocrinology, vol. 23, no. 1, pp. 5-12, 2007.

[21] N. Wang, B. Liu, L. Liang et al., "Antiangiogenesis therapy of endometriosis using PAMAM as a gene vector in a noninvasive animal model," BioMed Research International, vol. 2014, Article ID 546479, 11 pages, 2014.

[22] A. Taguchi, O. Wada-Hiraike, K. Kawana et al., "Resveratrol suppresses inflammatory responses in endometrial stromal cells derived from endometriosis: a possible role of the sirtuin 1 pathway," Journal of Obstetrics and Gynaecology Research, vol. 40, no. 3, pp. 770-778, 2014.

[23] G. Laste, I. C. de Macedo, J. R. Rozisky, F. R. da Silva, W. Caumo, and I. L. S. Torres, "Melatonin administration reduces inflammatory pain in rats," Journal of Pain Research, vol. 5, pp. 359362, 2012.

[24] G. Yildirim, R. Attar, F. Ozkan, B. Kumbak, C. Ficicioglu, and N. Yesildaglar, "The effects of letrozole and melatonin on surgically induced endometriosis in a rat model: a preliminary study," Fertility and Sterility, vol. 93, no. 6, pp. 1787-1792, 2010.

[25] A. Schwertner, C. C. Conceição Dos Santos, G. D. Costa et al., "Efficacy of melatonin in the treatment of endometriosis: a phase II, randomized, double-blind, placebo-controlled trial," Pain, vol. 154, no. 6, pp. 874-881, 2013.

[26] M. Amir, S. Romano, S. Goldman, and E. Shalev, "Plexin-B1, glycodelin and MMP7 expression in the human fallopian tube and in the endometrium," Reproductive Biology and Endocrinology, vol. 7, article 152, 2009.
[27] H. Nguyen, V. S. Ivanova, L. Kavandi, G. C. Rodriguez, G. L. Maxwell, and V. Syed, "Progesterone and 1,25-dihydroxyvitamin D 3 inhibit endometrial cancer cell growth by upregulating semaphorin 3B and semaphorin 3F," Molecular Cancer Research, vol. 9, no. 11, pp. 1479-1492, 2011.

[28] A. Lasco, A. Catalano, and S. Benvenga, "Improvement of primary dysmenorrhea caused by a single oral dose of vitamin D: results of a randomized, double-blind, placebo-controlled study," Archives of Internal Medicine, vol. 172, no. 4, pp. 366-367, 2012.

[29] T. Worzfeld and S. Offermanns, "Semaphorins and plexins as therapeutic targets," Nature Reviews Drug Discovery, vol. 13, no. 8, pp. 603-621, 2014.

[30] F. Leuschner, P. Dutta, R. Gorbatov et al., "Therapeutic siRNA silencing in inflammatory monocytes in mice," Nature Biotechnology, vol. 29, no. 11, pp. 1005-1010, 2011.

[31] S. K. Banu, J. Lee, V. O. Speights Jr., A. Starzinski-Powitz, and J. A. Arosh, "Selective inhibition of prostaglandin E2 receptors EP2 and EP4 induces apoptosis of human endometriotic cells through suppression of ERK1/2, AKT, NF $\mathcal{B}$, and $\beta$-catenin pathways and activation of intrinsic apoptotic mechanisms," Molecular Endocrinology, vol. 23, no. 8, pp. 1291-1305, 2009.

[32] J. Lee, S. K. Banu, T. Subbarao, A. Starzinski-Powitz, and J. A. Arosh, "Selective inhibition of prostaglandin E2 receptors EP2 and EP4 inhibits invasion of human immortalized endometriotic epithelial and stromal cells through suppression of metalloproteinases," Molecular and Cellular Endocrinology, vol. 332, no. 1-2, pp. 306-313, 2011.

[33] J. Lee, S. K. Banu, R. C. Burghardt, A. Starzinski-Powitz, and J. A. Arosh, "Selective inhibition of prostaglandin E2 receptors EP2 and EP4 inhibits adhesion of human endometriotic epithelial and stromal cells through suppression of integrin-mediated mechanisms," Biology of Reproduction, vol. 88, no. 3, article 77, 2013.

[34] J. Puurunen, T. Piltonen, K. Puukka et al., "Statin therapy worsens insulin sensitivity in women with polycystic ovary syndrome (PCOS): a prospective, randomized, double-blind, placebo-controlled study," Journal of Clinical Endocrinology and Metabolism, vol. 98, no. 12, pp. 4798-4807, 2013.

[35] S. Oriaifo and N. Oriaifo, "Metformin lowers C-reactive protein levels and improves the modified brief pain inventory scores in a woman with endometriosis-associated chronic pelvic pain: a case report and literature review," International Journal of Drug Development and Technology, vol. 4, no. 2, pp. 79-85, 2014.

[36] D. Y. Oh and E. Walenta, "The role of omega-3 fatty acid receptor GPR120 in insulin resistance," International Journal of Obesity Supplements, vol. 4, pp. S14-S16, 2014.

[37] L. Zhang, J.-B. Hao, L.-S. Ren, J.-L. Ding, and L.-R. Hao, “The aldosterone receptor antagonist spironolactone prevents peritoneal inflammation and fibrosis," Laboratory Investigation, vol. 94, no. 8, pp. 839-850, 2014.

[38] N. Dalbeth, T. J. Lauterio, and H. R. Wolfe, "Mechanism of action of colchicine in the treatment of gout," Clinical Therapeutics, vol. 36, no. 10, pp. 1465-1479, 2014.

[39] R. Kurt, N. Pinar, A. Karateke et al., "Protective effects of colchicine in an experimental rat endometriosis model: histopathological evaluation and assessment of TNF- $\alpha$ levels," Reproductive Sciences, vol. 22, no. 2, pp. 258-263, 2014.

[40] K. E. May, J. Villar, S. Kirtley, S. H. Kennedy, and C. M. Becker, "Endometrial alterations in endometriosis: a systematic review of putative biomarkers," Human Reproduction Update, vol. 17, no. 5, pp. 637-653, 2011. 
[41] K. E. May, S. A. Conduit-Hulbert, J. Villar, S. Kirtley, S. H. Kennedy, and C. M. Becker, "Peripheral biomarkers of endometriosis: a systematic review," Human Reproduction Update, vol. 16, no. 6, Article ID dmq009, pp. 651-674, 2010.

[42] A. Fassbender, A. Vodolazkaia, P. Saunders et al., "Biomarkers of endometriosis," Fertility and Sterility, vol. 99, no. 4, pp. 1135$1145,2013$.

[43] A. Akoum, M. Al-Akoum, A. Lemay, R. Maheux, and M. Leboeuf, "Imbalance in the peritoneal levels of interleukin 1 and its decoy inhibitory receptor type II in endometriosis women with infertility and pelvic pain," Fertility and Sterility, vol. 89, no. 6, pp. 1618-1624, 2008.

[44] Y. Ohata, T. Harada, H. Miyakoda, F. Taniguchi, T. Iwabe, and N. Terakawa, "Serum interleukin-8 levels are elevated in patients with ovarian endometrioma," Fertility and Sterility, vol. 90, no. 4, pp. 994-999, 2008.

[45] S. E. Rier, A. K. Parsons, and J. L. Becker, "Altered interleukin6 production by peritoneal leukocytes from patients with endometriosis," Fertility and Sterility, vol. 61, no. 2, pp. 294-299, 1994.

[46] B. Seeber, M. D. Sammel, X. Fan et al., "Panel of markers can accurately predict endometriosis in a subset of patients," Fertility and Sterility, vol. 89, no. 5, pp. 1073-1081, 2008.

[47] M. Ulukus, E. C. Ulukus, E. N. Tavmergen Goker, E. Tavmergen, W. Zheng, and A. Arici, "Expression of interleukin-8 and monocyte chemotactic protein 1 in women with endometriosis," Fertility and Sterility, vol. 91, no. 3, pp. 687-693, 2009.

[48] C. M. Kyama, L. Overbergh, A. Mihalyi et al., "Endometrial and peritoneal expression of aromatase, cytokines, and adhesion factors in women with endometriosis," Fertility and Sterility, vol. 89, no. 2, pp. 301-310, 2008.

[49] I. Kligman, J. A. Grifo, and S. S. Witkin, "Expression of the $60 \mathrm{kDa}$ heat shock protein in peritoneal fluids from women with endometriosis: implications for endometriosis-associated infertility," Human Reproduction, vol. 11, no. 12, pp. 2736-2738, 1996.

[50] G. M. Borrelli, M. S. Abrão, and S. Mechsner, "Can chemokines be used as biomarkers for endometriosis? A systematic review," Human Reproduction, vol. 29, no. 2, pp. 253-266, 2014.

[51] J. Donnez, P. Smoes, S. Gillerot, F. Casanas-Roux, and M. Nisolle, "Vascular endothelial growth factor (VEGF) in endometriosis," Human Reproduction, vol. 13, no. 6, pp. 1686-1690, 1998.

[52] P. Dziunycz, Ł. Milewski, D. Radomski et al., "Elevated ghrelin levels in the peritoneal fluid of patients with endometriosis: associations with vascular endothelial growth factor (VEGF) and inflammatory cytokines," Fertility and Sterility, vol. 92, no. 6, pp. 1844-1849, 2009.

[53] K.-F. Lee, Y.-L. Lee, R. W. S. Chan et al., "Up-regulation of endocrine gland-derived vascular endothelial growth factor but not vascular endothelial growth factor in human ectopic endometriotic tissue," Fertility and Sterility, vol. 93, no. 4, pp. 1052-1060, 2010.

[54] N. Esfandiari, J. Ai, Z. Nazemian, M. H. Javed, L. Gotlieb, and R. F. Casper, "Expression of glycodelin and cyclooxygenase2 in human endometrial tissue following three-dimensional culture," The American Journal of Reproductive Immunology, vol. 57, no. 1, pp. 49-54, 2007.

[55] F. J. Cornillie, J. M. Lauweryns, M. Seppala, L. Riittinen, and P. R. Koninckx, "Expression of endometrial protein PP14 in pelvic and ovarian endometriotic implants," Human Reproduction, vol. 6, no. 10, pp. 1411-1415, 1991.
[56] P. R. Koninckx, L. Riittinen, M. Seppala, and F. J. Cornillie, "CA-125 and placental protein 14 concentrations in plasma and peritoneal fluid of women with deeply infiltrating pelvic endometriosis," Fertility and Sterility, vol. 57, no. 3, pp. 523-530, 1992.

[57] J. S. Lewis, K. Meeke, C. Osipo et al., "Intrinsic mechanism of estradiol-induced apoptosis in breast cancer cells resistant to estrogen deprivation," Journal of the National Cancer Institute, vol. 97, no. 23, pp. 1746-1759, 2005.

[58] C.-Y. Li, J.-H. Lang, H.-Y. Liu, and H.-M. Zhou, "Expression of annexin-1 in patients with endometriosis," Chinese Medical Journal, vol. 121, no. 10, pp. 927-931, 2008.

[59] M.-H. Wu, P.-C. Chuang, Y.-J. Lin, and S.-J. Tsai, "Suppression of annexin A2 by prostaglandin E2 impairs phagocytic ability of peritoneal macrophages in women with endometriosis," Human Reproduction, vol. 28, no. 4, pp. 1045-1053, 2013.

[60] C. Calhaz-Jorge, A. P. Costa, M. C. Santos, and M. L. PalmaCarlos, "Soluble intercellular adhesion molecule 1 in the peritoneal fluid of patients with endometriosis correlates with the extension of peritoneal implants," European Journal of Obstetrics Gynecology and Reproductive Biology, vol. 106, no. 2, pp. 170-174, 2003.

[61] E. Somigliana, P. Viganò, M. Candiani, I. Felicetta, A. M. di Blasio, and M. Vignali, "Use of serum-soluble intercellular adhesion molecule-1 as a new marker of endometriosis," Fertility and Sterility, vol. 77, no. 5, pp. 1028-1031, 2002.

[62] A.-M. Steff, D. Gagné, M. Pagé, P. Hugo, and D. Gosselin, “Concentration of soluble intercellular adhesion molecule-1 in serum samples from patients with endometriosis collected during the luteal phase of the menstrual cycle," Human Reproduction, vol. 19, no. 1, pp. 172-178, 2004.

[63] P. Viganò, E. Somigliana, B. Gaffuri, R. Santorsola, M. Busacca, and M. Vignali, "Endometrial release of soluble intercellular adhesion molecule 1 and endometriosis: relationship to the extent of the disease," Obstetrics and Gynecology, vol. 95, no. 1, pp. 115-118, 2000.

[64] L. Bordin, C. Fiore, G. Don et al., "Evaluation of erythrocyte band 3 phosphotyrosine level, glutathione content, CA-125, and human epididymal secretory protein E4 as combined parameters in endometriosis," Fertility and Sterility, vol. 94, no. 5, pp. 1616-1621, 2010.

[65] J. Kitawaki, H. Ishihara, H. Koshiba et al., "Usefulness and limits of CA-125 in diagnosis of endometriosis without associated ovarian endometriomas," Human Reproduction, vol. 20, no. 7, pp. 1999-2003, 2005.

[66] T. S. Patrelli, R. Berretta, S. Gizzo et al., "CA 125 serum values in surgically treated endometriosis patients and its relationships with anatomic sites of endometriosis and pregnancy rate," Fertility and Sterility, vol. 95, no. 1, pp. 393-396, 2011.

[67] S. Kennedy, A. Bergqvist, C. Chapron et al., "ESHRE guideline for the diagnosis and treatment of endometriosis," Human Reproduction, vol. 20, no. 10, pp. 2698-2704, 2005.

[68] A. Vodolazkaia, Y. El-Aalamat, D. Popovic et al., "Evaluation of a panel of 28 biomarkers for the non-invasive diagnosis of endometriosis," Human Reproduction, vol. 27, no. 9, pp. 26982711, 2012.

[69] N. Galazis, P. Athanasias, and N. Pisal, "Biochemical markers for endometriosis: a long way to go," Human Reproduction, vol. 29, no. 10, pp. 2352-2352, 2014.

[70] G. M. Borrelli, M. S. Abrão, and S. Mechsner, "Reply: biochemical markers for endometriosis: a long way to go," Human Reproduction, vol. 29, no. 10, p. 2353, 2014. 
[71] N. Tokushige, R. Markham, P. Russell, and I. S. Fraser, "Different types of small nerve fibers in eutopic endometrium and myometrium in women with endometriosis," Fertility and Sterility, vol. 88, no. 4, pp. 795-803, 2007.

[72] N. Tokushige, R. Markham, P. Russell, and I. S. Fraser, "High density of small nerve fibres in the functional layer of the endometrium in women with endometriosis," Human Reproduction, vol. 21, no. 3, pp. 782-787, 2006.

[73] O. Donnez, M. Soares, S. Defrère et al., "Nerve fibers are absent in disease-free and eutopic endometrium, but present in endometriotic (especially deep) lesions," Journal of Endometriosis, vol. 5, no. 2, pp. 68-76, 2013.

[74] A. Bokor, C. M. Kyama, L. Vercruysse et al., "Density of small diameter sensory nerve fibres in endometrium: a semi-invasive diagnostic test for minimal to mild endometriosis," Human Reproduction, vol. 24, no. 12, pp. 3025-3032, 2009.

[75] A. Giannini, F. Bucci, S. Luisi et al., "Brain-derived neurotrophic factor in plasma of women with endometriosis," Journal of Endometriosis, vol. 2, no. 3, pp. 144-150, 2010.

[76] A. S. Browne, J. Yu, R.-P. Huang, A. M. C. Francisco, N. Sidell, and R. N. Taylor, "Proteomic identification of neurotrophins in the eutopic endometrium of women with endometriosis," Fertility and Sterility, vol. 98, no. 3, pp. 713-719, 2012.

[77] S.-Z. Jia, Y. Yang, J. Lang, P. Sun, and J. Leng, "Plasma miR-17$5 \mathrm{p}, \mathrm{miR}-20 \mathrm{a}$ and miR-22 are down-regulated in women with endometriosis," Human Reproduction, vol. 28, no. 2, pp. 322330, 2013.

[78] W.-T. Wang, Y.-N. Zhao, B.-W. Han, S.-J. Hong, and Y.-Q. Chen, "Circulating microRNAs identified in a genome-wide serum microRNA expression analysis as noninvasive biomarkers for endometriosis," Journal of Clinical Endocrinology and Metabolism, vol. 98, no. 1, pp. 281-289, 2013.

[79] S. Liu, S. Gao, X. Y. Wang, and D. B. Wang, "Expression of miR-126 and Crk in endometriosis: MiR-126 may affect the progression of endometriosis by regulating Crk expression," Archives of Gynecology and Obstetrics, vol. 285, no. 4, pp. 10651072, 2012.

[80] L. Shen, S. Yang, W. Huang et al., "MicroRNA23a and MicroRNA23b deregulation derepresses SF-1 and upregulates estrogen signaling in ovarian endometriosis," The Journal of Clinical Endocrinology and Metabolism, vol. 98, no. 4, pp. 1575-1582, 2013.

[81] L. A. Ramn, A. Braza-Bols, J. Gilabert-Estells et al., "microRNAs expression in endometriosis and their relation to angiogenic factors," Human Reproduction, vol. 26, no. 5, pp. 1082-1090, 2011.

[82] A. Braza-Boïls, J. Gilabert-Estellés, L. A. Ramón et al., "Peritoneal fluid reduces angiogenesis-related microRNA expression in cell cultures of endometrial and endometriotic tissues from women with endometriosis," PLoS ONE, vol. 8, no. 4, Article ID e62370, 2013.

[83] K. Toor, J. M. Wessels, S. K. Agarwal, N. Leyland, and W. G. Foster, "Clinical markers of endometriosis: have we been too quick to judge?” Medical Hypotheses, vol. 82, no. 4, pp. 493-501, 2014.

[84] R. Casper, "Introduction: new tools for enhancing collaborative endometriosis research," Fertility and Sterility, vol. 102, no. 5, pp. 1211-1212, 2014.

[85] C. M. Becker, M. R. Laufer, P. Stratton et al., "World Endometriosis Research Foundation Endometriosis Phenome and Biobanking Harmonisation Project: I. Surgical phenotype data collection in endometriosis," Fertility and Sterility, vol. 102, no. 5, pp. 1213-1222, 2014.

[86] A. F. Vitonis, K. Vincent, N. Rahmioglu et al., "World Endometriosis Research Foundation Endometriosis Phenome and biobanking harmonization project: II. Clinical and covariate phenotype data collection in endometriosis research," Fertility and Sterility, vol. 102, no. 5, pp. 1223-1232, 2014.

[87] N. Rahmioglu, A. Fassbender, A. Vitonis et al., "World Endometriosis Research Foundation Endometriosis Phenome and Biobanking Harmonization Project: III. Fluid biospecimen collection, processing, and storage in endometriosis research," Fertility and Sterility, vol. 102, no. 5, pp. 1233-1243, 2014.

[88] A. Fassbender, N. Rahmioglu, A. Vitonis et al., "World Endometriosis Research Foundation Endometriosis Phenome and Biobanking Harmonisation Project: IV. Tissue collection, processing, and storage in endometriosis research," Fertility and Sterility, vol. 102, no. 5, pp. 1244-1253, 2014.

[89] N. Sinaii, S. D. Cleary, M. L. Ballweg, L. K. Nieman, and P. Stratton, "High rates of autoimmune and endocrine disorders, fibromyalgia, chronic fatigue syndrome and atopic diseases among women with endometriosis: a survey analysis," Human Reproduction, vol. 17, no. 10, pp. 2715-2724, 2002.

[90] A. S. Melo, J. C. Rosa-E-Silva, A. C. J. De Sá Rosa-E-Silva, O. B. Poli-Neto, R. A. Ferriani, and C. S. Vieira, "Unfavorable lipid profile in women with endometriosis," Fertility and Sterility, vol. 93, no. 7, pp. 2433-2436, 2010.

[91] J. A. L. Gemmill, P. Stratton, S. D. Cleary, M. L. Ballweg, and N. Sinaii, "Cancers, infections, and endocrine diseases in women with endometriosis," Fertility and Sterility, vol. 94, no. 5, pp. 1627-1631, 2010.

[92] S. Kinugasa, K. Shinohara, and A. Wakatsuki, "Increased asymmetric dimethylarginine and enhanced inflammation are associated with impaired vascular reactivity in women with endometriosis," Atherosclerosis, vol. 219, no. 2, pp. 784-788, 2011.

[93] L. Santoro, F. D’Onofrio, S. Campo et al., "Endothelial dysfunction but not increased carotid intima-media thickness in young European women with endometriosis," Human Reproduction, vol. 27, no. 5, pp. 1320-1326, 2012.

[94] R. Mormile, G. Vittori, and U. Squarcia, "How much truth is there in the association between endometriosis and atherosclerosis?" Journal of Pediatric Endocrinology and Metabolism, vol. 26, no. 7-8, pp. 797-798, 2013.

[95] D. A. Shoskes, D. Prots, J. Karns, J. Horhn, and A. C. Shoskes, "Greater endothelial dysfunction and arterial stiffness in men with chronic prostatitis/chronic pelvic pain syndromea possible link to cardiovascular disease," Journal of Urology, vol. 186, no. 3, pp. 907-910, 2011.

[96] C. C. M. Buis, F. E. van Leeuwen, T. M. Mooij, and C. W. Burger, "Increased risk for ovarian cancer and borderline ovarian tumours in subfertile women with endometriosis," Human Reproduction, vol. 28, no. 12, pp. 3358-3369, 2013.

[97] H. S. Kim, T. H. Kim, H. H. Chung, and Y. S. Song, "Risk and prognosis of ovarian cancer in women with endometriosis: a meta-analysis," British Journal of Cancer, vol. 110, no. 7, pp. 18781890, 2014.

[98] R. Ferreira, C. Vieira, J. Rosa-e-Silva, A. Rosa-e-Silva, A. Nogueira, and R. Ferriani, "Effects of the levonorgestrelreleasing intrauterine system on cardiovascular risk markers in patients with endometriosis: a comparative study with the GnRH analogue," Contraception, vol. 81, no. 2, pp. 117-122, 2010. 
[99] M. Y. Donath, "Targeting inflammation in the treatment of type 2 diabetes: time to start," Nature Reviews Drug Discovery, vol. 13, no. 6, pp. 465-476, 2014.

[100] M. M. Murphy, L. M. Barraj, J. H. Spungen, D. R. Herman, and R. K. Randolph, "Global assessment of select phytonutrient intakes by level of fruit and vegetable consumption," British Journal of Nutrition, vol. 112, no. 6, pp. 1004-1018, 2014.

[101] Y. Jiang, S.-H. Wu, X.-O. Shu et al., "Cruciferous vegetable intake is inversely correlated with circulating levels of proinflammatory markers in women," Journal of the Academy of Nutrition and Dietetics, vol. 114, no. 5, pp. 700-708, 2014. 


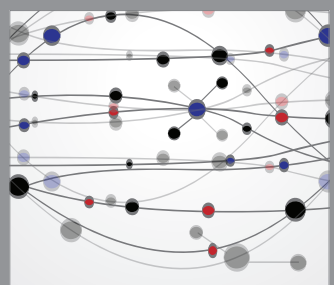

The Scientific World Journal
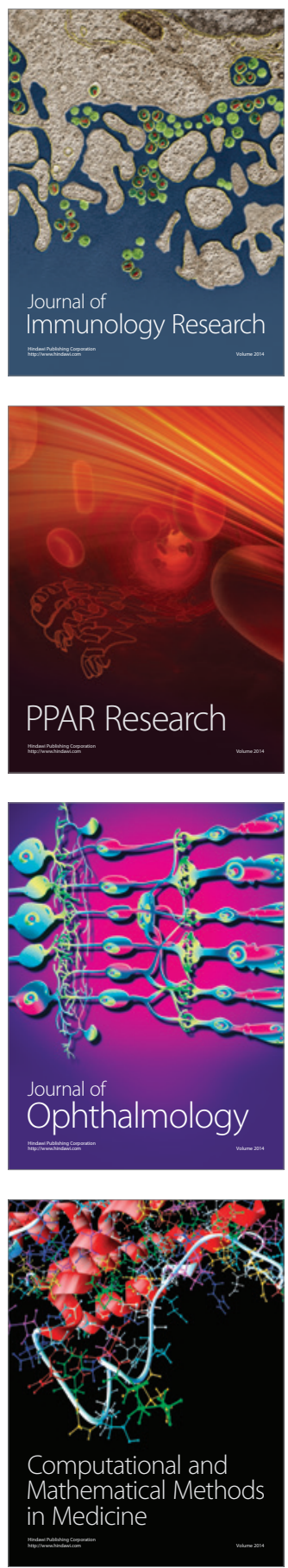

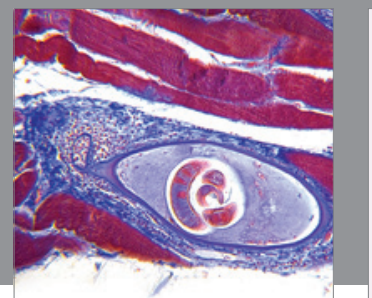

Gastroenterology

Research and Practice
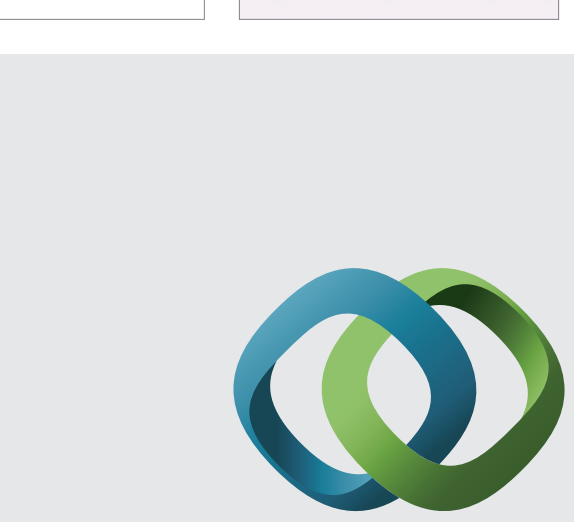

\section{Hindawi}

Submit your manuscripts at

http://www.hindawi.com
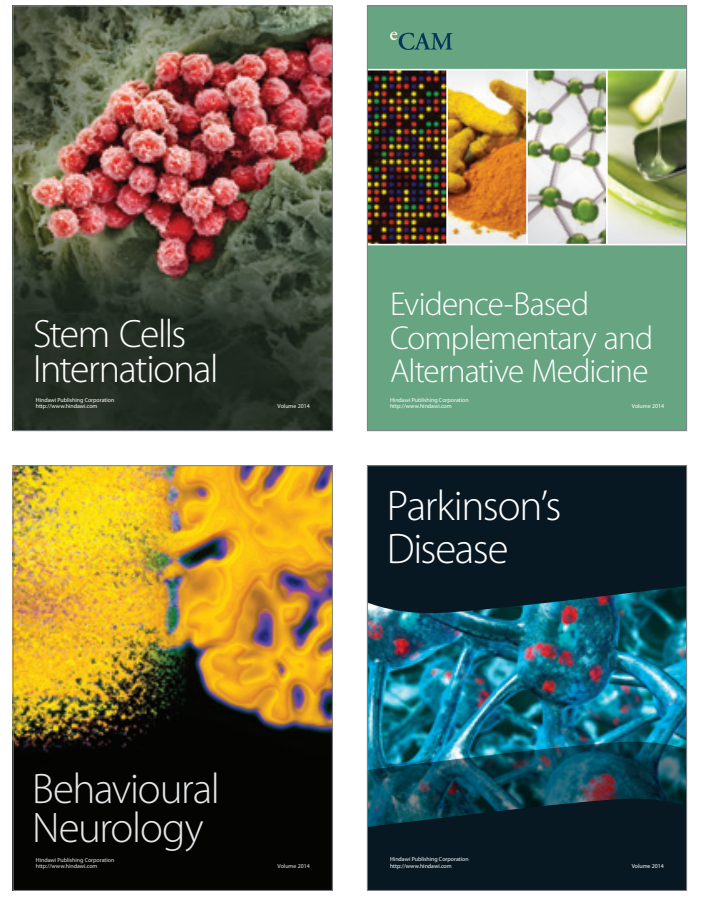
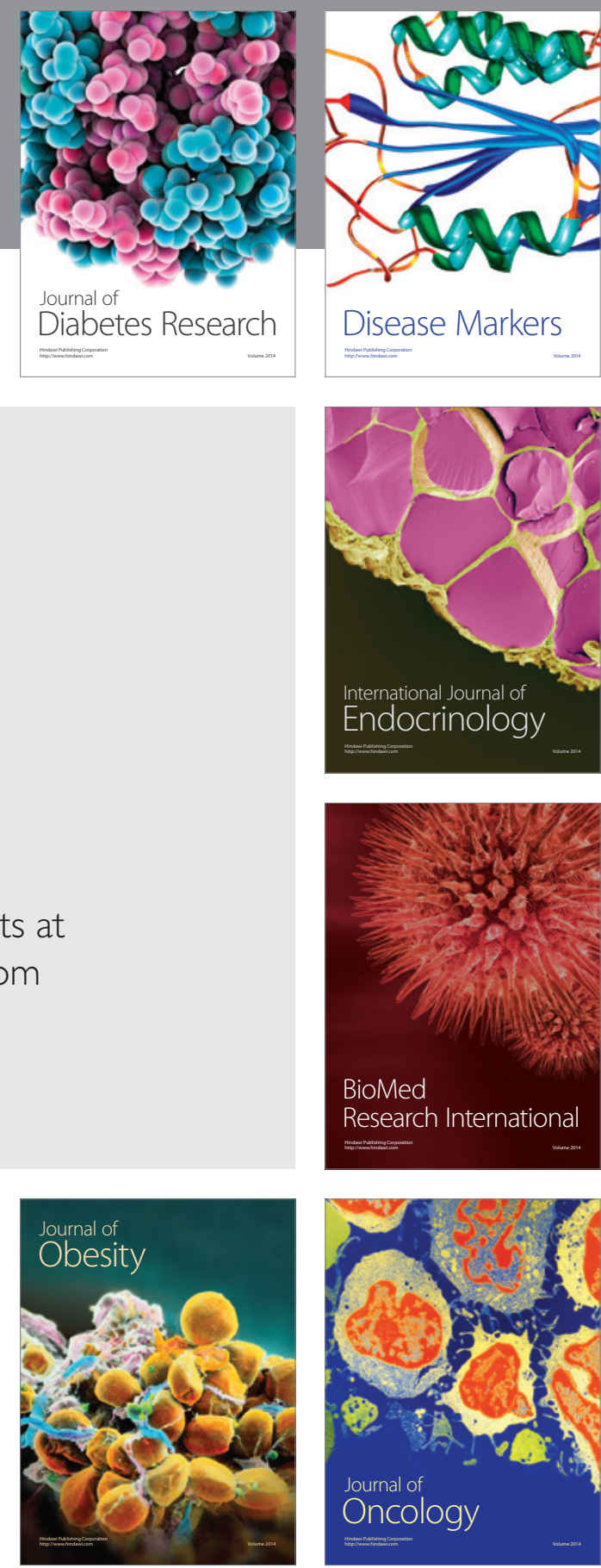

Disease Markers
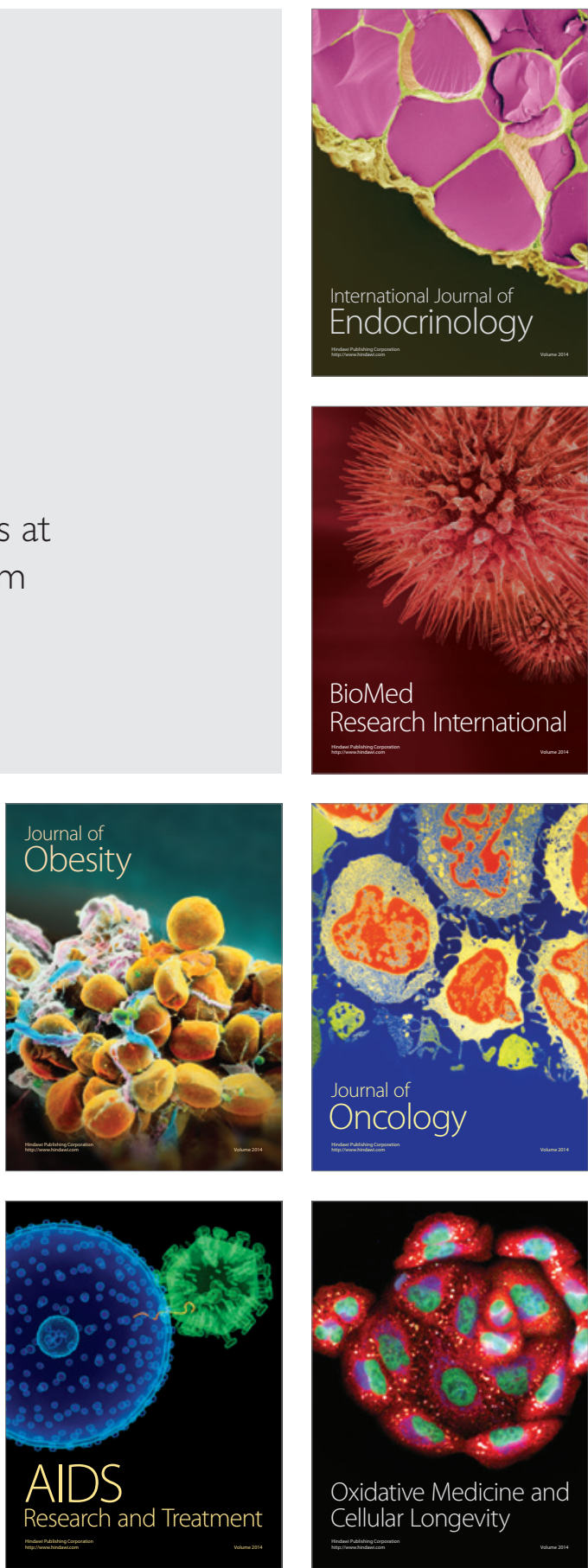